\title{
ARGUMENTAÇÃO EM DISCURSOS SOBRE FORMAÇÃO SUPERIOR E ATUAÇÃO NA ÁREA DE LETRAS: ANÁLISE EM RELATÓRIOS DE ESTÁGIO SUPERVISIONADO
}

\author{
ARGUMENTATION IN DISCOURSES ON HIGHER EDUCATION \\ AND ACTING IN THE AREA OF LANGUAGE: ANALYSIS OF \\ REPORTS OF SUPERVISED TRAINING
}

\author{
Gilton Sampaio de Souza* \\ Universidade do Estado do Rio Grande do Norte, Pau dos Ferros, RN, Brasil \\ Maria Leidiana Alves** \\ Universidade do Estado do Rio Grande do Norte, Pau dos Ferros, RN, Brasil
}

\begin{abstract}
Resumo: Partilhando do pressuposto de que a argumentação é constitutiva da linguagem, objetivamos analisar aqui as teses defendidas por autores/oradores de relatórios de estágio supervisionado, em discursos sobre formaçãa e a atuacç̃o na área de Letras de uma IES pública, considerando as teses como centrais ao processo argumentativo e as articulando às técnicas argumentativas empregadas e ao auditório a que se destinam os oradores. Os pressupostos teóricos advêm da Nova Retórica (PERELMAN e OLBRECHTS-TYTECA, 2005) e da contribuição de estudiosos da área. Nos processos argumentativos dos cinco relatórios observamos a existência de diferentes teses, ancoradas em argumentos de autoridade, superação, direção, modelo/antimodelo e da pessoa e seus atos, sob pontos de vista variados: (i) nõo há associação entre a prática desenvolvida pelo estagiário e a prática desenvolvida pelo professor da educacā̃o básica; (ii) é necessário articular teoria e prótica no ensino de português; e (iii) 0 estáaio fundamenta o desenvolvimento de uma metodologia inovadora para ensino. As conclusões apontam distanciamentos entre as teses sobre o ensino de Língua Portuguesa oferecido na educacaço superior e na educacạ̃o básica, revelando argumentos às vezes antagônicos sobre a formacção e a atuação nesses dois niveis de ensino.
\end{abstract}

Palavras-chave: Nova Retórica; Discurso e Argumentaçãó; Tese; Relatórios de estágio; Formação superior em Letras.

Abstract: Sharing the assumption that argumentation is constitutive of the language, we aim to analyze here theses defended by authors/orators generated from supervised internship reports in discourses about education and performance in the Letters' area of a public $H E E$, considering the theses as central to the argumentative process and articulating them to the employed argumentative techniques and to the auditory intended for the orators. The theoretical assumptions come from the New Rhetoric (PERELMAN and OLBRESCHTS-TYTECA,

* Professor Doutor da Universidade do Estado do Rio Grande do Norte - UERN, Pau dos Ferros, RN, Brasil; giltonssouza@gmail.com

* * Doutoranda do Programa de Pós-graduação em Letras - PPGL, Universidade do Estado do Rio Grande do Norte - UERN, Pau dos Ferros, RN, Brasil; leidiana_alves2007@yahoo.com.br 
Linha D'Água (Online), São Paulo, v. 29, n. 2, p. 271-293, dez. 2016

2005) and from the contribution of area scholars. In the argumentative processes of the five reports, we noticed the existence of different theses anchored in arguments of authority, overcoming, direction, model/antimodel and of the person and his acts, from different points of view: (i) there is no association between the intern's developed practice and the basic education teacher's developed practice; (ii) it is necessary to link theory and practice in Portuguese teaching; and (iii) the internship grounds the development of an innovative methodology for teaching. The findings point distances between the theses on the Portuguese language education offered in higher education and in basic education, revealing sometimes antagonistic arguments about education and performance in these two levels of teaching.

Keywords: New Rhetoric; Discourse and Argumentation; Thesis; IIternship Reports; Higher Education in Language.

\section{Introdução}

A reflexão a que nos propomos fazer aqui está pautada nos pressupostos da Nova Retórica (PERELMAN e OLBRECHTS-TYTECA, 2005) e tem como foco a argumentação em discursos que perpassam a formação e a atuação docente em uma universidade pública brasileira. Em especial, objetivamos analisar as teses defendidas por autores/oradores de relatórios de estágio supervisionado em discursos sobre a formação e a atuação na área de Letras de uma IES pública, considerando as teses como centrais ao processo argumentativo e as articulando às técnicas argumentativas empregadas e ao auditório a que se destinam os oradores.

A opção pelo estudo da argumentação na produção escrita no Ensino Superior, mais especificamente do gênero acadêmico relatório de estágio supervisionado, na perspectiva da Nova Retórica, justifica-se pela necessidade de maior compreensão sobre como ocorrem os processos argumentativos em gêneros do discurso acadêmico e de entendimento sobre o que pensam os estagiários de Letras sobre o seu próprio curso. Em especial, essa temática instiga-nos também a pensarmos sobre como os oradores/estagiários organizam argumentativamente suas ideias por meio de teses e técnicas argumentativas sobre a formação superior que recebem no curso de Letras, sobre a atuação do professor de Língua Portuguesa da educação básica, que os estagiários observaram no período de Estágio Supervisionado, e sobre como os próprios oradores/estagiários ministram suas aulas de Língua Portuguesa em escolas do Ensino Médio.

O corpus da pesquisa é constituído de fragmentos de relatórios de estágio supervisionado escritos por alunos do $6^{\circ}$ período do curso Letras de uma IES 
pública. Analisamos cinco relatórios de alunos do curso de Letras/Português, que foram escritos por ocasião da disciplina Orientação e Estágio Supervisionado II ${ }^{1}$, ofertada no curso de Letras da IES em estudo, sendo coordenada por um professor do curso, que é também o supervisor acadêmico de estágio. De acordo com as orientações dessa disciplina, o aluno/estagiário foi orientado a atender as seguintes recomendações técnicas para a construção do relatório de estágio: registrar por escrito o que é vivenciado durante o estágio, relatando e refletindo sobre as atividades e experiências adquiridas tanto na fase de diagnóstico quanto na fase da regência; relatar as atividades observadas, relacionando-as à teoria estudada, e relatar as atividades desenvolvidas por ele, durante a fase de regência, também com a preocupação de fazer a articulação entre teoria e prática.

Para a construção do relatório de estágio, os alunos também são orientados a escreverem seus trabalhos em acordo com a seguinte estrutura composicional e funcional do gênero: (i) introdução, contendo aspectos gerais do estágio e as bases teóricas; (ii) relato das atividades realizadas e experiências adquiridas na fase de diagnóstico; (iii) ensino e aprendizagem na fase de regência de classe; (iv) ensino e aprendizagem nas oficinas pedagógicas; (v) considerações finais; (vi) referências bibliográficas; e (vii) anexos. Em termos gerais, o relatório de estágio supervisionado dessa instituição congrega diferentes seções com a finalidade de fazer com que o estagiário reflita, discuta e analise os diversos aspectos que compõem o ensino de Língua Portuguesa durante o estágio, deixando registradas nesse documento as principais contribuições que esse momento oportuniza na formação profissional do estudante de Letras. (Fonte: ALVES², 2011).

Os pressupostos teóricos para este estudo advêm da Nova Retórica (PERELMAN e OLBRECHTS-TYTECA, 2005), tendo também a contribuição de

\footnotetext{
1 A disciplina "Orientação e Estágio Supervisionado II" é ofertada no $6^{\circ}$ período do curso de Letras-Português, com carga horária de 240 horas a serem ministradas no Ensino Médio. Essa disciplina é precedida pela disciplina "Orientação e Estágio Supervisionado I", com foco no Ensino Fundamental.

2 Esse artigo traz parte das reflexões e dos resultados da pesquisa de nossa Dissertação de Mestrado, intitulada "O ethos de estudantes de Letras em relatórios de estágio de diferentes IES brasileiras" (ALVES, 201 1), defendida no Programa de Pós-Graduação em Letras (PPGL) da UERN.
} 
Linha D'Água (Online), São Paulo, v. 29, n. 2, p. 271-293, dez. 2016

estudiosos da argumentação no discurso que se utilizam da Nova Retórica como teoria de base, especialmente em pesquisa institucionais sobre argumentação em discursos acadêmicos, com destaque para dissertações (COSTA, 2010; LIMA, 2011; ALVES, 2011; COSTA, 2014 e RAULINO, 2015) e para artigos publicados em periódicos (SOUZA, PEREIRA e ALVES, 2009; SOUZA, COSTA e BARBOSA JÚNIOR, 2012; SOUZA e BESSA, 2011; SOUZA e COSTA, 2009; ALVES e SOUZA, 2013; entre outros).

Esta pesquisa sobre a argumentação em discursos acadêmicos na área de Letras vem também somar-se às pesquisas acima citadas e a outras, desenvolvidas ou em desenvolvimento junto à Linha de Pesquisa em "Estudos de processos argumentativos", do Grupo de Pesquisa em Produção e Ensino de Texto (GPET), certificado pela UERN e cadastrado no CNPq. Além disso, o seu relato aqui, em formato de artigo, está organizado em quatro seções, a Introdução, em que apresentamos aspectos centrais e norteadores de toda pesquisa; as Orientaçóes Teóricas, na qual tratamos da definição das principais categorias teóricas aqui utilizadas; a seção de análise, intitulada Argumentação em discursos sobre formação e atuação na área de Letras: análise, que subdividimos em quatro subseções para analisarmos e interpretarmos os discursos, com base em excertos selecionados dos relatórios; e a Conclusão, momento em que retomamos resultados do trabalho, destacando alguns dados da pesquisa realizada para, em seguida, trazermos as Referências consultadas e citadas.

\section{Orientações teóricas}

As reflexões teóricas que empreendemos aqui assumem a compreensão de que a dimensão argumentativa da linguagem está pressuposta no discurso, seja ele oral ou escrito, e que se realiza na relação dialógica entre orador e auditório, que são elementos constitutivos do processo argumentativo. Faremos aqui uma definição teórica de algumas categorias que fundamentam esse trabalho: argumentação, discurso, processo argumentativo, teses e técnicas argumentativas.

A argumentação se apresenta como uma ação humana que visa a convencer e/ou persuadir o público a que se destina da validade de suas teses. No intuito de compreender o funcionamento e o objetivo maior da argumentação retórica, 
Linha D'Água (Online), São Paulo, v. 29, n. 2, p. 271-293, dez. 2016

recorremos a Perelman e Olbrechts-Tyteca (2005, p. 50) que, no Tratado da Argumentação, definem:

O objetivo de toda argumentação [...] é provocar ou aumentar a adesão dos espíritos às teses que se apresentam a seu assentimento: uma argumentação eficaz é a que consegue aumentar essa intensidade de adesão, de forma que se desencadeie nos ouvintes a ação pretendida (ação positiva ou abstração) ou, pelo menos, crie neles uma disposição para a ação, que se manifestará no momento oportuno.

A teoria da argumentação no discurso, nos postulados da Nova Retórica, apresenta-se como uma abordagem discursiva e retórica da argumentação, que pressupõe a interação e a argumentatividade como princípios da linguagem humana, verbal e não-verbal, e que se concretiza entre os interlocutores nos processos argumentativos. Entender essa definição de argumentação pressupõe compreender o discurso como realização desses processos. Para Perelman e Olbrechts-Tyteca (2005, p. 213), o discurso se constitui como um ato simbólico de produção de sentido, desenvolvido por um orador/autor, em diálogo com seu possível ouvinte/interlocutor, a quem pretende convencer e/ou persuadir; é um meio e traz indícios de produção e circulação de sentido, de significados, de teses, pressupostos, argumentos etc.

A compreensão de argumentação com base na Nova Retórica pressupõe o entendimento de que ela se efetiva em processos argumentativos que constituem os discursos, tanto na modalidade oral quanto na modalidade escrita, nos diferentes gêneros e áreas de atividade humana. Os processos argumentativos são mecanismos discursivos e retóricos pelos quais os oradores organizam suas ideias, de forma que articulem a imagem revelada pelos próprios oradores, a apresentação de teses, técnicas e argumentos, entre outros elementos, com o auditório presumível, público-alvo a quem o orador se dirige. Para Perelman e Olbrechts-Tyteca (2005, p. 07), "todo discurso se dirige a um auditório, sendo muito frequente esquecer que se dá o mesmo com todo escrito". Desse modo, a argumentação retórica é constitutiva não somente do discurso falado, em situações presenciais, mas também nos textos escritos que são sempre condicionados, consciente ou inconscientemente, por aqueles a quem pretende dirigir-se. 
Sendo a argumentação um ato que pressupõe interação, é preciso que consideremos, conforme Perelman (2004, p. 325), que "qualquer argumentação, para ser eficaz, deve apoiar-se em teses admitidas pelo auditório". De acordo com o autor, a tese assume uma função central no processo da argumentação. Ela está ligada à parte lógica, racional, da argumentação, ao logos. Considerando essa assertiva, conforme Souza (2008), entre os posicionamentos que devemos assumir ao analisarmos argumentativamente os textos, estão algumas definições operacionais para melhor compreensão dos efeitos argumentativos do discurso. Compartilhamos, portanto, da afirmação de Perelman (2004) que vincula a eficácia da argumentação à aceitação das teses admitidas pelo auditório.

Assim, nas práticas discursivas, o orador apresenta teses e procura convencer seu auditório da veracidade delas, que se apresentam como sínteses de proposições que afirmam ou negam a verdade de fatos ou presunções. As teses se apresentam como pontos de vista que revelam posicionamentos até mesmo divergentes, uma vez que

El contenido de una afirmación siempre forma parte de uma proposición en la que se refiere. En uma difencia de opinión, hay dos posiciones distintas que se toman respecto de la proposición que contiene una determinada afirmación ${ }^{3}$ (EEMEREN, GROOTENDORST, HENKEMANS, 2006, p. 25).

As teses, portanto, se definem como proposições que afirmam ou negam algo, sendo que toda proposição carrega em si um ponto de vista do orador, consciente ou inconscientemente.

Em qualquer discurso de qualquer esfera de atividade humana, o sujeito falante/escritor está sempre argumentando, dialogando com seu auditório presumido, defendendo ideias, pontos de vista. Para tanto, esse sujeito se utiliza, consciente ou inconscientemente, de técnicas discursivas e argumentativas para conseguir a adesão de seus interlocutores às teses apresentadas. Essas técnicas argumentativas,

3 O conteúdo de uma afirmação sempre é parte de uma proposição pela qual se atribui uma certa propriedade ou qualidade às pessoas ou às coisas a que elas se referem. Em uma diferença de opinião, há dois posicionamentos distintos que se referem à proposição que contém uma determinada afirmação. (Tradução livre). 
Linha D'Água (Online), São Paulo, v. 29, n. 2, p. 271-293, dez. 2016

conforme definem Perelman e Olbrechts-Tyteca (2005), apresentam-se em dois grandes grupos: das associações e das dissociações.

O grupo de técnicas argumentativas por associações de noções se subdivide em três subgrupos, em que os argumentos são produzidos por meio de aproximação e associação de ideias, noções, objetos, valores etc, e se classificam conforme descritas a seguir: (i) argumentação quase-lógica, na qual se destacam os argumentos de comparação, argumentação pelo sacrifício, pela regra de justiça etc; (ii) argumentação baseada na estrutura do real, que se apresenta em argumentos por ligações de sucessão, (pragmático, superação e direção) e pelas ligações de coexistência (argumento de autoridade, ligação simbólica, a pessoa e seus atos); e (iii) argumentação que fundamenta a estrutura do real, que tem ênfase os argumentos pelo exemplo, pelo modelo e pelo antimodelo. O grupo de técnicas argumentativas por dissociação de noções se subdivide em diferente pares hierarquizados pelos quais o orador busca separar noções que, de alguma forma, parecem ser sinônimas ou similares. Citam-se, como exemplo, os pares teoria/prática, meio/fim, ato/pessoa etc.

Após essas reflexões sobre as orientações teóricas que dão sustentação a este trabalho, passamos a análise de aspectos da argumentação em discursos que constituem os relatórios de estágio supervisionado, considerando as categorias de teses, técnicas argumentativas e argumentos, como partes constitutivas do processo argumentativo e fundamentais para a interpretação dos discursos objetos de estudo desse trabalho.

\section{Argumentação em discursos sobre formação e atuação na área de Le- tras: análise dos dados}

Atemo-nos, neste tópico, a analisar a argumentação em discursos que constituem relatórios de estágio supervisionado e que tem como foco a formação e a atuação docente na área de Letras. Nessa análise, tomamos como base a identificação e interpretação da tese principal e, vinculados a ela, analisamos outros aspectos do processo argumentativo que dão sustentação à tese e aos argumentos defendidos. O foco está nas teses relacionadas à formação e atuação em sala de aula da educação básica, durante a experiência vivenciada pelos autores/oradores, na efetivação do estágio supervisionado, nas fases de diagnóstico e de regência. 
Linha D'Água (Online), São Paulo, v. 29, n. 2, p. 271-293, dez. 2016

Ao descrever e refletir sobre as experiências adquiridas na fase de diagnóstico e de regência, os autores/oradores defendem algumas teses sobre sua formação e atuação na área de Letras. Como são muitas as teses defendidas nos cinco relatórios, procuramos dar ênfase às teses mais recorrentes. Para isso, organizamos a análise em três tópicos, em que interpretamos a argumentação nos discursos que compreendem diferentes teses e fases do estágio supervisionado.

\subsection{Argumentos sobre formação e atuação docente no ensino de Língua Portuguesa}

Os discursos que perpassam os relatórios de estágio carregam consigo diferentes teses, que são estruturalmente elaboradas por meio de técnicas argumentativas. Uma das técnicas argumentativas mais recorrentes entre os discursos dos autores/oradores é a dissociação de noções sobre prática docente. Os autores/oradores buscam destacar que não há uma associação direta entre o que se faz na prática docente desenvolvida pelo estagiário de Letras, sob a orientação de um professor universitário, com o que se faz na prática docente desenvolvida pelo professor de Língua Portuguesa da educação básica, por isso ressaltam sempre a necessidade de se dissociar a noção do que é ensinar a Língua Portuguesa em cada uma dessas situações.

Nos discursos analisados, a prática de ensino do professor da educação básica é sempre considerada inferior, tradicional, falha, em contraponto à prática de ensino realizada pelo estagiário, que é sempre defendida como sendo superior, eficaz. No caso do autor/orador no relatório O-R2 ${ }^{4}$, temos o discurso sobre o diagnóstico do ensino de Língua Portuguesa desenvolvido por um professor da educação básica, com destaque para suas carências, tradicionalismo e rejeição por parte dos alunos:

\section{Excerto 1:}

Mas, o que podemos perceber de imediato nas aulas de língua portuguesa que observamos nesta turma é que eles apresentam uma grande carência de leitura,

4 Códigos utilizados para identificação dos relatórios de estágio supervisionado: O-R2, que significa $\mathrm{O}$ = orador/autor do relatório; $\mathrm{R}$ = relatório; e 2 = número de ordem do relatório na catalogação geral. 
Linha D'Água (Online), São Paulo, v. 29, n. 2, p. 271-293, dez. 2016

falta de atenção, e em alguns casos antipatia explícita em relação à disciplina. Os alunos em grande parte reclamam quando o professor propõe atividades de leitura e, principalmente, de produção textual. Isso deve ser entendido, primeiramente, pela falta de estímulo e de inovação nas aulas de língua materna, tendo em vista que elas quase sempre seguem a mesma trilogia - texto (relacionado ao conteúdo literário do bimestre); conteúdo gramatical proposto pelo livro didático e seguidos de exercícios mecânicos de regras para memorização; e, produções textuais, nas quais os temas são relacionados às temáticas literárias propostas ou de escolhas livres. O que até certo ponto, apresentam-se como metodologias contrárias às propostas do PCNEM de Língua Portuguesa: Propõe-se, no nível do Ensino Médio, a formação geral, em oposição à formação específica; o desenvolvimento da capacidade de pesquisar, buscar informações, analisá-los e selecioná -los; a capacidade de aprender, criar, formular, ao invés do simples exercício de memorização. (BRASIL, 2006, p. 16).

Dessa forma, é preciso que os alunos sejam instigados a prática de leitura e de exercícios que desenvolvam o seu pensamento crítico reflexivo para que eles possam criar a capacidade de se posicionar criticamente a determinado texto ou mesmo exercício de compreensão, e não ficarem no nível de mera decodificação de palavras para decorar um determinado conteúdo. (O-R2, p. 08-09).

No excerto acima exposto, a prática docente observada e a prática proposta pelo autor/orador nos permitem perceber um processo argumentativo estruturado sob os argumentos por dissociação de noções, conforme discutido acima, e por argumentos que se baseiam na estrutura do real, com destaque para os argumentos pragmáticos, e que fundamentam a estrutura do real, especialmente pelo modelo/ antimodelo. Logo no início, o autor/orador apresenta a realidade do ensino de Língua Portuguesa, com destaque para a carência de leitura e para a rejeição explícita da disciplina por parte dos alunos. Utilizando-se do argumento pelo vínculo causal, baseado na estrutura do real, o autor/orador atribui a antipatia dos alunos à falta de estímulo e de inovação nas aulas de língua materna, estando associado ao argumento pragmático, uma vez que destaca a consequência, neste caso, desfavorável do ensino tradicional, apoiado na mesma trilogia do texto, conteúdo gramatical com exercícios mecânicos do livro didático e produções textuais relacionadas a temáticas propostas ou livres. Além de classificar tal metodologia como tradicional, o autor/orador apresenta-a como contrária às propostas dos PCNEM 
Linha D'Água (Online), São Paulo, v. 29, n. 2, p. 271-293, dez. 2016

de Língua Portuguesa, que seria, para ele, um modelo de ensino. Para tanto, recorre ao argumento de autoridade quando cita os documentos oficiais para reforçar sua tese de que o ensino de Língua Portuguesa desenvolvido pelo professor é frágil e contrário às propostas de ensino vigentes. Desse modo, o autor/orador reforça a sua argumentação por meio de técnicas de argumentação baseada na estrutura do real e também que fundamentam a estrutura do real, por meio do argumento de autoridade (documentos oficiais do MEC) e do antimodelo, em que as aulas se tornam "exercícios de mera decodificação".

Em outro momento, o autor/orador de O-R2, reforça a defesa de sua tese por meio da dissociação de noções, afirmando que há uma distinção qualitativa entre a prática de ensino desenvolvida pelo professor da educação básica e a prática desenvolvida pelo estagiário. Por meio dessa dissociação, defende que sua prática, diferentemente da observada, esteve em conformidade com os objetivos primordiais do ensino de língua materna no Ensino Médio, prescritos nos documentos oficiais - a leitura, a produção e a análise linguística:

Excerto 2:

[...] foi possível constatar que os objetivos primordiais do ensino de língua materna - leitura, produção e análise lingüística, são, na maioria das vezes, atropelados e desvinculados das reais necessidades e carências dos alunos. [...] Partindo dessa constatação, nos propomos a seguir uma prática de ensino que abarcasse tais objetivos e promovesse ao aluno a possibilidade de interação com a linguagem e com suas funções por meio de textos, entendo-os em suas manifestações lingüísticas sociais e comunicacionais, já que é por meio de sua língua materna que o aluno é capaz de se inserir nas relações da sociedade, atuando de forma crítica, reflexiva e consciente. (O-R2, p. 19).

Nesse excerto, em discursos sobre a formação e atuação na área de Letras, o autor/orador defende a tese de que sua prática possibilitou um ensino produtivo, interacional, "atuando de forma crítica, reflexiva e consciente" o que o diferencia do ensino desvinculado das reais necessidade e carências dos alunos que vem sendo ofertado no Ensino Médio. O autor/orador desenvolve sua tese utilizando-se, entre outras, de uma técnica argumentativa que se baseia na estrutura do real, 
Linha D'Água (Online), São Paulo, v. 29, n. 2, p. 271-293, dez. 2016

sobretudo, por meio do argumento de autoridade, citando os documentos oficiais como parâmetros e orientações legais que devem seguidos.

$\mathrm{O}$ autor/orador de O-R3 também desenvolve o processo argumentativo em defesa de sua prática por meio da dissociação de noções, entre o diagnóstico de uma metodologia tradicional e do desenvolvimento de uma prática superior, funcional, buscando suprir as deficiências:

\section{Excerto 3:}

Acreditamos que em meio às deficiências encontradas com relação às abordagens tradicionais, limitadoras e um tanto quanto prescritivas, que interpelam o ensino do português, conseguimos fazer a aplicação funcional dessas teorias de ensino em sala de aula durante a regência de classe. Neste sentido, podemos afirmar que o que falta nas aulas de Língua Portuguesa é a adequação das teorias de ensino à realidade dos educandos. (O-R3, p. 14-15).

Nos discursos sobre o ensino de Língua Portuguesa, o autor/orador de O-R3 argumenta que as abordagens são tradicionais, limitadoras e um tanto quanto prescritivas. Como forma de mostrar que em sua atuação foi, além disso, afirma ter conseguido fazer a aplicação funcional das teorias de ensino em sala de aula, que conseguiu articular teoria e prática. Ancorado no argumento ato pessoa, afirma, ao concluir, que o que ele fez é exatamente o que falta nas aulas de Língua Portuguesa: a adequação das teorias de ensino à realidade dos educandos.

\subsection{Argumentos sobre teoria e prática em articulação entre documentos oficiais e teóricos da área}

No processo argumentativo dos relatórios em análise, observamos que a defesa da tese de que é importante articular teoria e prática no processo de ensino aprendizagem, durante a experiência do estágio, perpassa todos eles. Essa articulação, como nos apresentam os autores/oradores, dá-se em três aspectos: primeiro, no sentido de colocar em prática, como eles destacam, os conhecimentos adquiridos no curso; segundo, articular esses conhecimentos relativos a pressupostos teóricos na discussão e na reflexão sobre o ensino de Língua Portuguesa observado, e terceiro, ao apresentar os pressupostos e documentos da área como basilares para 
Linha D'Água (Online), São Paulo, v. 29, n. 2, p. 271-293, dez. 2016

a prática de ensino por eles desenvolvida enquanto estagiários, que culminam na elaboração do relatório de estágio: "buscamos fazer um trabalho consciente e reflexivo, relacionando os pressupostos teóricos acerca do ensino de língua e linguagem com a prática vivenciada em sala de aula" (O-R3, p. 02). Como percebemos, o autor/orador defende sua tese por meio de uma argumentação baseada na estrutura do real, por ligações de coexistência, que relaciona a pessoa e seus atos, como forma de conferir valor, qualidade à sua pessoa pelos atos positivos praticados, conforme defendem Perelman e Olbrechts-Tyteca (2005), atrelando-os a uma imagem de estagiário competente.

No caso abaixo, o autor/orador, dá continuidade a esse processo argumentativo, baseado no argumento da pessoa e seus atos, em defesa de sua tese, ao afirmar ter procurado fazer uma discussão teórico-reflexiva sobre as metodologias de ensino de Língua Portuguesa de acordo com os direcionamentos dos Parâmetros Curriculares Nacionais - PCN:

\section{Excerto 4:}

Para tanto, achamos conveniente fazer uma conveniente (sic) fazer uma discussão teórica-reflexiva sobre as metodologias utilizadas no processo de ensino-aprendizagem de Língua Portuguesa e seus efeitos no contexto de sala de aula, de acordo com os direcionamentos apresentados pelos Parâmetros Curriculares Nacionais (PCN). (O-R3, p. 02).

Neste caso, a preocupação reside em refletir sobre a metodologia de ensino observada com base nos documentos oficiais que são tomados como sendo referencial teórico. Neste fio do discurso do autores/orador de O-R3, percebemos o estabelecimento de um diálogo com um auditório mais imediato e particular, o professor da disciplina de Orientação e Estágio Supervisionado II, dado o trabalho com os PCN, realizado em sala de aula durante as aulas teóricas, conforme consta no programa da referida disciplina.

Sendo os PCN base de apoio para a vivência da experiência do estágio para os autores/oradores, entendemos sua proposta de procurar atender à tríplice proposta do referido documento que propõe a articulação dos três eixos: leitura, produção e análise linguística. Nesse ínterim, os autores/oradores intentam defender 
Linha D'Água (Online), São Paulo, v. 29, n. 2, p. 271-293, dez. 2016

sua prática, colocando-a em conformidade com o documento, contemplando os três pilares de sustentação do ensino. Acompanhemos:

Excerto 5:

Com base nisso, buscamos realizar a leitura em sala de aula de forma que os educandos dessem uma resposta ao que leram, posicionando-se criticamente diante do texto. Sobre a prática de leitura, Jurado e Rojo (2006, p. 39) afirmam que, no contato com textos, o aluno precisa [...]. (O-R3, p. 13).

Para justificar, dar mais credibilidade à sua prática sobre o ensino da leitura, considerada um dos eixos do ensino proposto pelo documento oficial, o autor/ orador mostra que atua em conformidade com pressupostos teóricos e curriculares vigentes e mais uma vez utiliza-se da voz dos autores da área como argumentos de autoridade para dar sustentabilidade, credibilidade à sua prática e de si próprio enquanto profissional, recorrendo, portanto, também à argumentação que relaciona a pessoa e seus atos.

A produção de texto, considerada o segundo eixo do ensino de língua portuguesa, também é fundamentada pelos documentos oficiais. O autor/orador de O-R3, por exemplo, afirma ter fundamentado sua prática de produção textual nas diretrizes dos PCNEM, assim como o autor/orador de O-R4, que mostra ter contemplado os três eixos justificando o trabalho com leitura, interpretação, produção e refacção, com base nos gêneros textuais. $\mathrm{O}$ autor/orador demonstra ter domínio do assunto, estar atualizado e coerente com a teoria que, conforme os PCN, permeia a prática de ensino de Língua Portuguesa no momento, quando, através do argumento de definição - argumentação quase-lógica, segundo Perelman e O1brechts-Tyteca (2005), instrumento pelo qual se busca fornecer o sentido verdadeiro de algo, dar a conhecer discursivamente, identificar, esclarecer determinado termo - conceitua os gêneros textuais, conforme os PCN.

Excerto 6:

As atividades de leitura, interpretação, produção e refacção de textos foram baseados nos Gêneros Textuais, que atualmente permeiam o estudo com a Língua Portuguesa em seus mais diversos níveis. Como aponta os PCN's (1998, p. 21): 'Todo texto se organiza dentro de determinado gênero em função das intenções 
comunicativas, como parte das condições de produção dos discursos, as quais geram usos sociais que os determinam'. (O-R4, p. 13).

Já no tópico destinado à fase de regência, o autor/orador de O-R5 inicia falando sobre a importância da educação na vida do ser humano nos dias atuais. Nesse sentido, projeta a imagem de estagiário responsável com o planejamento, que concebe a educação como o melhor caminho e assume a concepção de linguagem proposta nos PCN com o "objetivo de alcançar grandes resultados na prática". Em seu discurso, revela uma argumentação baseada na estrutura do real, por meio do argumento da direção que pode ser usado, segundo Perelman e Olbrechts-Tyteca (2005, p. 321) "cada vez que uma meta pode ser apresentada como um ponto de referência, uma etapa numa certa direção [...] Esse argumento responde à pergunta: aonde se quer chegar?

Excertos 7 e 8:

[...] observamos tamanha responsabilidade que é o de planejar. Como (sic) o objetivo de alcançar grandes resultados na prática, pois mediante essas observações feitas partimos neste momento para a prática, com a concepção de linguagem descrita pelos PCNs. (O-R5, p. 09).

[...] 'é nessa perspectiva [da concepção de linguagem proposta pelos pens] que, o docente passa a utilizar uma metodologia, em que seja possível alcançar o objetivo pretendido, e que o aluno passa interagir com os textos apresentados no ambiente escolar'. (O-R5, p. 13).

Ancorado também na argumentação baseada na estrutura do real, pelo argumento pragmático, especialmente no excerto 8 , o autor/orador destaca o que poderia levar o docente a alcançar grandes resultados na prática. Por meio do vínculo causal, atribui, de certa forma, tais resultados à concepção de linguagem adotada ser a dos documentos oficiais. Esses resultados pretendidos são no sentido, na direção de promover mudanças, como podemos observar no discurso de O-R5 "com o objetivo de que aconteça mudança, partimos desenvolvimento da prática, que foi a regência [...]” (O-R5, p. 09). Esses discursos pressupõem uma dissociação de noções, pois, se há necessidade de que ocorram mudanças com as práticas que 
Linha D'Água (Online), São Paulo, v. 29, n. 2, p. 271-293, dez. 2016

serão por eles desenvolvidas, têm-se indícios de que a prática observada necessita ser melhorada. Com isso, eles projetam a imagem de estagiários/professores superiores/inovadores que se propõem a promover mudanças com sua prática.

Assim, a perspectiva de trabalho com a linguagem proposta pelos PCN é colocada como modelo a ser seguido, como condição para que o docente alcance seus objetivos e proporcione a interação dos alunos com os textos. Nesse processo argumentativo desenvolvido pelo autor/orador O-R5, percebemos uma analogia quando ele destaca seu trabalho em conformidade com os documentos oficiais; ora, se os PCN são parâmetros de ensino, modelo, e eu atuo em conformidade com eles, também defendo minha prática como sendo um modelo.

Ao defender a tese de que se preocupa com o planejamento das aulas para alunos do Ensino Médio, o autor/orador de O-R4 revela uma imagem de um profissional preocupado com o planejamento, que destina atenção aos PNC. Mais uma vez, ele apresenta-se como coerente com os pressupostos do documento oficial.

Excerto 9:

Vale lembrar que, por se tratar de um trabalho a ser desenvolvido no ensino médio (etapa final da educação básica), tivemos uma preocupação maior com o planejamento das nossas aulas. Analisamos com atenção o que propõem os PCN's (2002, p. 21). (O-R4, p. 12).

Nessa perspectiva, os autores/oradores, com base no diagnóstico realizado, apontam a necessidade de articulação teoria e prática, ressaltando a importância de trabalhar em conformidade com os documentos oficiais e com os teóricos da área. Como, de acordo com as constatações apresentadas, o ensino não contempla este aspecto, defendem sua importância e mostram que atuaram de forma a atender e a suprir essa necessidade e, assim, superar a prática observada e colocar-se enquanto modelo a ser seguido e revelando no discurso um diálogo com a instituição, no caso, o curso de Letras de sua instituição de ensino marcando sua relação com o saber, demonstrando seu pertencimento a determinado grupo dominante. 
Linha D'Água (Online), São Paulo, v. 29, n. 2, p. 271-293, dez. 2016

\subsection{Argumentos sobre o estágio supervisionado e a atuação do estagiário}

Outro ponto de vista, apresentado pelos autores/oradores em seus relatórios, é o de que o estágio fundamenta o desenvolvimento de uma metodologia inovadora, diferenciada, superior, dinâmica, reflexiva, eficaz, um modelo a ser seguido. Em síntese, a tese defendida pelos autores/oradores em seus relatórios é a de que o estagiário intervém, positivamente, na realidade observada. Vejamos em O-R1:

\section{Excerto 10:}

Com base em todos os estudos feitos para a realização de nosso trabalho, tanto na fase de diagnóstico quanto na fase de regência, procuramos dar um direcionamento que subsidiasse, de maneira mais eficaz, os procedimentos metodológicos realizados em sala de aula. Buscamos, sobretudo, suprir alguns fatores preocupantes observados na fase de diagnóstico, trazendo à tona uma postura metodológica que contemplasse as três facetas indispensáveis ao ensino de língua materna: leitura, produção de texto e análise linguística, dentro de seus entrecruzamentos. (O-R1, s.p. Considerações finais).

O autor/orador de O-R1 se coloca na condição de estagiário, profissional competente, eficiente, que, tanto no diagnóstico quanto na regência, procurou desenvolver procedimentos metodológicos mais eficazes. Dessa forma, o discurso do autor/orador nos dá indícios de que a prática observada era menos eficaz, colocando sua atuação em posição de superioridade, o que é reafirmado em seguida, quando mostra que, em sua prática docente, procurou, sobretudo, suprir fatores preocupantes encontrados. Nesse sentido, assume que a prática observada apresenta alguma falta, algo a ser melhorado com sua atuação, e acrescenta que trouxe à tona as três facetas indispensáveis ao ensino de Língua Portuguesa, configurado como sendo uma contribuição, apresentar algo ainda não existente, de modo a colocar, assim, sua prática como sendo superior. Ao colocar sua prática como superior à prática observada, utiliza-se do argumento da superação, argumento baseado na estrutura do real, que consiste, segundo Perelman e Olbrechts-Tyteca (2005), em insistir na possibilidade de ir sempre além.

$\mathrm{O}$ autor/orador de $\mathrm{O}-\mathrm{R} 1$ se preocupa em estar sempre reafirmando a importância do estágio para a formação do aluno de Letras. Ele argumenta que o estágio 
Linha D'Água (Online), São Paulo, v. 29, n. 2, p. 271-293, dez. 2016

é uma oportunidade de desenvolver a articulação teoria x prática e reconhece a necessidade de o estagiário desempenhar o papel do professor, de planejar, selecionar, refletir e contemplar aspectos que venham enriquecer a constituição de saberes de cada aluno, em especial de alunos da terceira série do Ensino Médio, quando muitas vezes, segundo o autor/orador, o olhar docente é direcionado apenas para o vestibular. Mais uma vez, o ponto de vista observado no discurso desse autor/orador é o de quem conhece e se preocupa com a realidade do ensino. Daí não se constituir apenas enquanto estagiário que realiza o estágio apenas em cumprimento a uma exigência de uma instituição, como podemos ver no seu discurso ao discorrer sobre a seção ensino $x$ aprendizagem na fase de regência de classe:

Excerto 11:

A fase de regência é um momento singular. É um período em que o estagiário tem a oportunidade de desenvolver um trabalho prático concernente aos estudos teóricos vistos na Academia. Por isso, o estagiário necessita, assim como todo professor, planejar, selecionar, refletir e contemplar o que, pioneiramente, possa enriquecer os saberes constituídos na formação de cada aluno, principalmente no ensino médio - em particular a terceira série - onde muitas vezes o docente direciona um olhar unicamente ligado ao vestibular. (O-R1. Ensino x aprendizagem na fase de regência de classe).

Nesse sentido, de acordo com os autores/oradores dos relatórios, a exemplo de O-R1, as experiências adquiridas durante o estágio contribuem para sua formação enquanto estudantes e futuros profissionais da área, colocando em prática, em suas atuações futuras, os conhecimentos adquiridos. As práticas por eles desenvolvidas e defendidas são colocadas como modelos a serem seguidos, inclusive por eles mesmos, conforme aponta O-R1.

Os discursos dos autores/oradores apresentam a proposição de que o estágio desempenha um papel importante por fundamentar a atuação com práticas inovadoras, eficazes e que ultrapassem as diversas dificuldades do sistema de ensino. Aqui se revela o caráter de superação da prática docente realizada em relação à prática observada, o que se dá por meio da dissociação de noções e que a coloca como modelo a ser seguido. Este configura, portanto, o sentido maior atribuído à atuação desses autores/oradores: o caráter de interventor, de inovador: 
Linha D'Água (Online), São Paulo, v. 29, n. 2, p. 271-293, dez. 2016

\begin{abstract}
Excerto 12:
[...] dessa forma, procuramos desenvolver um trabalho reflexivo que pudesse causar pequenas inferências diante da realidade encontrada no ensino da língua materna. (O-R4, p. 05).
\end{abstract}

Dessa maneira, o autor/orador assume a realização de um trabalho reflexivo e que interferisse na realidade encontrada. Em seu processo argumentativo, portanto, defende e sugere ter assumido a postura de um profissional reflexivo, superior/ inovador, que, apesar das dificuldades encontradas no ensino de Língua Portuguesa, proporcionou grandes contribuições para a formação enquanto futuros profissionais da área, como conclui, por exemplo, o autor/orador de O-R4.

Compartilhando desse ponto de vista, o autor/orador de O-R3, orienta a argumentação de seu discurso em função da defesa da tese de que a contribuição do estágio para a formação é fundamentar uma ótica inovadora e eficaz para o ensino de língua materna:

\footnotetext{
Excerto 13:

[...] consideramos que o estágio foi de grande relevância para nós, enquanto estudantes da língua e futuros profissionais de ensino, pois é diante da realidade correta da sala de aula que podemos estabelecer nas práticas pedagógicas, as quais precisam, e devem, estar fundamentadas através de uma ótica inovadora e eficaz para o ensino de língua materna. (O-R3, p. 16).
}

Nos discursos dos autores/oradores dos relatórios em estudo, conforme excerto acima, o estágio contribui decisivamente para a formação enquanto estudantes da língua e para atuações futuras, uma vez que proporciona o conhecimento de uma realidade em sala de aula e que a partir dela promove o estabelecimento de práticas pedagógicas fundamentadas numa ótica inovadora e eficaz para o ensino de língua materna, em oposição à prática observada e considerada por eles como tradicional e ineficaz. Esse processo argumentativo é ancorado na dissociação de noções, entre a prática docente observada e a prática docente sugerida, realizada pelo estagiário, o que figura, outrossim, na analogia: eu estou para a prática modelo, inovadora assim como o professor está para a prática antimodelo, tradicional. 
Linha D'Água (Online), São Paulo, v. 29, n. 2, p. 271-293, dez. 2016

Como pudemos acompanhar, no processo argumentativo construído pelos autores/oradores dos cinco relatórios de estágio, em defesa de suas teses, várias técnicas dão sustentação aos seus discursos que são direcionados a um determinado público, auditório. Sendo assim, os autores/oradores dialogam com um auditório particular, representado pelo professor da disciplina Orientação e estágio supervisionado II, com os documentos oficiais e teóricos da área quando defendem a tese de uma prática de ensino que articula teoria e prática. $\mathrm{O}$ diálogo se estende para o professor, que tem sua prática docente observada e discutida, para o aluno da educação básica, uma vez que a prática desenvolvida considera sua realidade, o que reafirma a tese de que é necessária a adequação do ensino à realidade do aluno e do ensino de Língua Portuguesa, e ainda, para o próprio curso de Letras ao discutir aspectos da formação e atuação dos estagiários, relacionados ao estágio supervisionado oferecido no referido curso.

\section{Conclusão}

Após o desenvolvimento dessa pesquisa acerca da argumentação em discursos acadêmicos (relatórios de estágio supervisionado) na área de Letras, passamos a fazer algumas ponderações e conclusões, mesmo que provisórias, em torno das questões teóricas aqui discutidas, dos corpora analisados e interpretados, e de suas pertinências e possíveis implicações aos estudos da argumentação, aos estudos dos discursos acadêmicos e também a aspectos do ensino de Língua Portuguesa nos cursos de Letras.

Com base nos dados e nas categorias teóricas analisadas, observamos que os estudos discursivos com base na Nova Retórica têm contribuído para a análise da argumentatividade da linguagem humana, que é constitutiva de todo discurso, para os estudos nos espaços acadêmicos em geral, e, em síntese, para pesquisas sobre argumentação na área acadêmica e em outras áreas, para análise e interpretação de processos argumentativos em discursos acadêmicos, mas em outros diferentes gêneros do discurso também.

Do ponto de vista da Nova Retórica, assumimos a posição de que o estudo do processo argumentativo de um texto não se esgota apenas na análise de um ou 
Linha D'Água (Online), São Paulo, v. 29, n. 2, p. 271-293, dez. 2016

outro de seus elementos constitutivos isoladamente, mas através da articulação entre eles, mesmo que, dada a necessidade de um recorte metodológico, tenhamos dado foco na tese e nos argumentos utilizados em função de um auditório presumido, nos discursos de relatórios de estágio supervisionado, escritos por estudantes do $7^{\circ}$ período do curso de Letras de uma IES pública.

Quanto ao objetivo traçado para este trabalho de analisar as teses defendidas por autores/oradores de relatórios de estágio supervisionado em discursos sobre a formação e a atuação na área de Letras de uma IES pública, considerando as teses como centrais ao processo argumentativo e as articulando às técnicas argumentativas empregadas e ao auditório a que se destinam os oradores, destacamos três teses centrais e constitutivas do processo argumentativo desenvolvido por eles sobre sua formação, a prática docente na área de Letras e sobre o estágio do referido curso:

(i) não há uma associação direta entre o que se faz na prática docente desenvolvida pelo estagiário de Letras, com o que se faz na prática docente desenvolvida pelo professor de Língua Portuguesa da educação básica - ancorada em técnicas argumentativas como o argumento por dissociação de noções, pragmático, modelo/antimodelo, vínculo causal e autoridade, quando dissociam a prática observada da prática por eles desenvolvida, apontando a necessidade do desenvolvimento de uma prática inovadora que é exatamente a que eles se propõem a desenvolver, constituindo-se enquanto profissionais superiores/ inovadores/modelos e associando sua prática docente à formação recebida no curso de Letras;

(ii) é importante articular teoria e prática no processo de ensino aprendizagem, durante a experiência do estágio - Por meio de argumentos como a pessoa e seus atos, definição, direção, pragmático, vínculo causal, modelo, analogia defendem a importância da articulação teoria e prática, tanto em sala de aula, quanto na escritura do relatório, recorrendo ainda ao argumento de autoridades, teóricos da área como também é unânime a preocupação com as propostas dos documentos oficiais (PCN e PCNEM), tanto em relação à prática docente observada, geralmente considerada falha por não considerar 
Linha D'Água (Online), São Paulo, v. 29, n. 2, p. 271-293, dez. 2016

os documentos, quanto em relação à sua prática, colocada como modelo por estar em conformidade com os documentos e teóricos da área; e

(iii) o estágio fundamenta o desenvolvimento de uma metodologia inovadora ao defenderem essa proposição, os autores/oradores, argumentam que o estagiário intervém, positivamente, na realidade observada. Para isso, recorrem a argumentos de superação, dissociação de noções, modelo/antimodelo, que fundamentam sua tese e o desenvolvimento de uma metodologia inovadora, diferenciada, superior, dinâmica, reflexiva, eficaz, um modelo a ser seguido.

Uma vez que na Nova Retórica o processo argumentativo pressupõe um auditório a quem o orador direciona seu discurso, nesses processos analisados, os autores/oradores projetam seu discurso para um auditório representado pelo professor da disciplina de Orientação e estágio supervisionado, pelo professor e alunos da educação básica, pelos teóricos da área e documentos oficiais, bem como, pelo próprio curso de Letras que regimenta e orientam, tanto o estágio, quanto a elaboração do relatório, trabalho final da disciplina. Esses dados nos levam a refletir sobre o papel da argumentação na análise do texto acadêmico, sobre o caráter dialógico e argumentativo desse discurso e sobre o papel assumido por cada sujeito envolvido nesse processo e refletido nesses discursos.

Um estudo dessa natureza é pertinente também por possibilitar, por meio de uma análise argumentativa, o conhecimento e a reflexão sobre os sentidos, os pontos de vista e as teses que se defendem e se ensinam sobre o ensino de língua portuguesa na educação superior e na educação básica. Os resultados trazidos, apontam para um distanciamento entre as propostas de ensino de Língua Portuguesa oferecidas na educação superior e na educação básica, revelando teses às vezes antagônicas sobre os dois níveis de ensino e que em função desses dados, acreditamos ser necessário aos professores formadores dos cursos de Letras rediscutirem o papel das disciplinas e de atividades de orientação em estágio supervisionado, especialmente, no sentido de que as atividades feitas durante essas disciplinas possam trazer mais contribuições e colaborações para o ensino de língua portuguesa na educação básica do que somente (ou quase somente) críticas e apontamentos de problemas que se verificam no ensino de Língua Portuguesa, no Ensino Básico. 
Linha D'Água (Online), São Paulo, v. 29, n. 2, p. 271-293, dez. 2016

\section{Referências}

ALVES, Maria Leidiana. O ethos de estudantes de Letras em relatórios de estágio de diferentes IES brasileiras. 2011. 254f. Dissertação (Mestrado Acadêmico em Letras). Universidade do Estado do Rio Grande do Norte, Pau dos Ferros, 2011.

ALVES, Maria Leidiana; SOUZA, Gilton Sampaio de. Na tensão de vozes, a (re)velação de imagens: o ethos de estudantes de Letras em relatórios de estágio. Diálogo das Letras, v. 2, p. 125$146,2013$.

COSTA, Elvis Alves da. Argumentação e memórias em depoimentos/narrativas de professores da UERN de Pau dos Ferros. 2014. Dissertação (Mestrado Acadêmico em Letras) - Universidade do Estado do Rio Grande do Norte. Pau dos Ferros, 2014.

COSTA, Rosa Leite da. Os egressos de Letras e seu discurso: da constituição do ethos aos sentidos sobre o curso. 2010. 171f. Dissertação (Mestrado em Letras) - Universidade do Estado do Rio Grande do Norte. Pau dos Ferros, 2010.

EEMEREN, Frans Van; GROOTENDORST, Rob; HENKEMANS, Francisca Snoeck. $A r-$ gumentación: análisis, evaluación, presentación. Buenos Aires: Biblos, 2006.

PERELMAN, Caim; OLBRECHTS-TYTECA. Lucie. Tratado de argumentação: a nova retórica. Trad. Maria Ermantina de Almeida Prado Galvão. 2. ed. São Paulo: Martins Fontes, 2005.

PERELMAN, Chaïm. Retóricas. Trad. Maria Ermantina de Almeida Prado Galvão. São Paulo: Martins Fontes, 2004.

RAULINO, Genisa Lima de Sousa. A argumentação e a produção de sentidos em textos de alunos do Ensino Médio e do Ensino Superior. 2015. Dissertação (Mestrado em Mestrado Acadêmico em Ensino) - Universidade do Estado do Rio Grande do Norte. Pau dos Ferros, 2015.

SOUZA, Gilton Sampaio de Argumentação no discurso: questões conceituais. In: FREITAS, Alessandra Cardozo de; RODRIGUES, Lílian de Oliveira; SAMPAIO, Maria Lúcia Pessoa (Org.). Linguagem, discurso e cultura: múltiplos objetos e abordagens. Mossoró: Queima $\mathrm{Bu}-$ cha, 2008.

SOUZA, G. S.; ALVES, M. L. Argumentação em discursos sobre formação superior e atuação na 
Linha D'Água (Online), São Paulo, v. 29, n. 2, p. 271-293, dez. 2016

; PEREIRA, Crígina Cibelle; ALVES, Maria Leidiana; Argumentação e dialogismo no texto acadêmico: os interlocutores em justificativas de monografia de graduação. In: HORA, Dermeval da (Org.). Anais do VI Congresso Internacional da ABRALIN. João Pessoa: UFPB/ ABRALIN, 2009.

; BESSA, José Cezinaldo Rocha. A produção textual no ensino superior: Análise de processos argumentativos em justificativas de monografias de graduação. Veredas, v. 1, p. 305-320, 2011.

; COSTA, Rosa Leite da. O professor de Letras e seu discurso: a constituição do ethos de professores do Ensino Superior. Letra Magna, v. x, p. 1-16, 2009.

; BARBOSA JUNIOR, Fernando Filgueira. A argumentação em discursos sobre o ensino superior na UERN: sentidos que constituem o Campus de Pau dos Ferros. EIDE $\mathcal{A} A$ - Revista Eletrônica de Estudos Integrados em Discurso e Argumentação, v. 02, p. 63-75, 2012.

Recebido em: 27/06/2016. Aprovado em: 20/08/2016. 